\title{
Multi-scale Characterization and Prediction of Coupled Subsurface Biogeochemical-Hydrological Processes
}

\author{
PI: Susan Hubbard ${ }^{* 1}$ \\ Co-PIs \& Collaborators: Ken Williams ${ }^{* 1}$, Carl Steefel ${ }^{* 1}$, Jill Banfield ${ }^{* 2}$, \\ Phil Long ${ }^{* 3}$, Lee Slater ${ }^{*}$, Steve Pride ${ }^{* 1}$ and Jinsong Chen ${ }^{* 1}$ \\ ${ }^{*}$ LBNL; ${ }^{* 2}$ UCB; ${ }^{* 3}$ PNNL: ${ }^{* 4}$ Rutgers Univ.
}

1. Research Objectives. To advance solutions needed for remediation of DOE contaminated sites, approaches are needed that can elucidate and predict reactions associated with coupled biological, geochemical, and hydrological processes over a variety of spatial scales and in heterogeneous environments. Our previous laboratory experimental experiments, which were conducted under controlled and homogeneous conditions, suggest that geophysical methods have the potential for elucidating system transformations that often occur during remediation. Examples include tracking the onset and aggregation of precipitates associated with sulfate reduction using seismic and complex resistivity methods (Williams et al., 2005; Ntarlagiannis et al., 2005) as well as estimating the volume of evolved gas associated with denitrification using radar velocity. These exciting studies illustrated that geophysical responses correlated with biogeochemical changes, but also that multiple factors could impact the geophysical signature and thus a better understanding as well as integration tools were needed to advance the techniques to the point where they can be used to provide quantitative estimates of system transformations.

Our current research includes theoretical, numerical, and experimental investigations, performed at the laboratory and the field scales, to determine if geophysical methods can be used to uniquely monitor system transformations. Our work is geared toward the Rifle, $\mathrm{CO}$, site, where other investigations are exploring the efficacy of electron-donor amendments for facilitating sustainable microbial reduction of U(VI) to U(IV) through a series of local-scale field experiments. Since the interplay between iron and sulfate reduction is believed to be of critical importance to the sustainable reduction of $\mathrm{U}(\mathrm{VI})$ at this site, quantitative interpretation of geophysical data in terms of redox state, exhaustion of bioavailable iron mineral phases, or onset of sulfate reduction is expected to greatly benefit the understanding and sustained remediation of uranium at the site.

2. Research Progress and Implications. Our project includes five key components: laboratory and field-scale experiments; development of petrophysical relationships; development of an estimation framework for integrating disparate, time-lapse datasets; and iteration between the geophysical monitoring estimates with predictions from advanced reactive transport models. This report summarizes the progress in our first year of a three year project in each of these areas.

2a) Laboratory studies. We have utilized site-derived materials to test a number of controlled mineralogical transformations at the laboratory scale during this year under static flow conditions. These transformations include (1) clay mineral alteration accompanying the reduction of structural ferric iron, (2) oxidation of FeS precipitates accompanying an increase in groundwater oxygen concentration, and (3) reduction of structural iron in bulk sediments through exposure to sulfide-rich groundwater. The goal of each of the three tests was to monitor the temporal change in the complex resistivity signal accompanying the transformation and to 
provide raw material for more detailed mineralogical characterization, including electron microscopy, x-ray diffraction, and analysis of acid-extractable metals. For the first test, the claysized fraction $(<2-\mu \mathrm{m})$ was isolated from the bulk sediments and reduced enzymatically using a site-isolated strain of Geobacter. The complex resistivity data revealed a slight decrease in both the phase response and the imaginary component of resistivity following bioreduction, suggesting that the alteration of clay minerals by microorganisms is capable of decreasing the polarization response of sediments containing iron-bearing phyllosilicates. While the primary mechanism responsible for the polarization decrease is believed to be the decrease in clay mineral surface area exposed to the pore fluid following reduction, additional factors, such as carbonate precipitation, may also be contributing to the observed decrease under field conditions. The second test utilized FeS precipitates obtained from enrichments of acetate- and ferrous ironamended site groundwater. The precipitates were first rinsed before being added to a column filled with silica sand and saturated with oxygenated groundwater. As oxidation of the FeS proceeded, complex resistivity data were collected. As indicated by a gradual change in color from black to orange, FeS oxidation proceeded over the course of several days. In contrast, the change in the complex resistivity response was rapid, with the polarization response characteristic of the FeS precipitates decreasing to that of the background silica sand within 24hours. The final test was designed to test the hypothesis that abiotic processes are capable of significantly altering the real component of resistivity through the precipitation of low conductivity phases, such as elemental sulfur created through the oxidation of bisulfide by ferric iron present in crystalline iron (oxy)hydroxides. Oxidized aquifer sediments were added to sulfide-rich groundwater lacking a readily available source of organic carbon (e.g. acetate) and the complex resistivity response was measured over the course of 2 weeks. During this time, the real component of conductivity (i.e. bulk conductivity) decreased by up to $16 \%$, presumably as a result of the precipitation of $\mathrm{S}^{0}$ and/or disseminated, disordered FeS. Over the same time period, the polarization response increased significantly $(44 \%$ at $10-\mathrm{Hz})$, most likely as a result of the precipitation of $\mathrm{FeS}$ and in agreement with our previous observations monitoring metal sulfide precipitation.

2b. Field Scale Characterization and Monitoring. Crosshole seismic, radar and complex resistivity, and SP data were collected this year between several well pairs and within all three flow cells at the Rifle Site. These data are being compared with electrical, geological, and flowmeter logs available from boreholes to assess hydrogeological heterogeneity at the site and to monitor responses associated with biostimulation experiments. Preliminary analysis suggests that an interpretation of heterogeneity across datasets is consistent across the datasets, and that the geophysical information should be useful for understanding hydrogeological variations across and within the sites.

Ideally, geophysical field-scale monitoring would be performed after all key features of the project (laboratory, reactive flow modeling, field characterization, and estimation framework) have been developed. However, during this year, we took advantage of ongoing field-scale biostimulation experiments to monitor the responses using time-lapse geophysical datasets. Most interesting are the responses observed in the time lapse, surface electrical resistivity tomographic (ERT) datasets and responses associated with self-potential (SP) measurements. The surface ERT datasets were collected perpendicular to experiments conducted during 2006 in what are called the '2004' and '2005' Rifle flow cells. In agreement with laboratory analysis (see Section 2a), these datasets displayed signatures associated with iron and 
sulfate reduction, respectively. Importantly, comparison of the ERT and characterization datasets suggests that biogeochemical transformations preferentially occurred in a thin, high-hydraulic conductivity zone. SP datasets (i.e. open circuit potential) were also collected in conjunction with the 2006 experiments conducted in the ' 2005 ' flow cell. With this technique, the magnitude of the cell potential can be estimated using the difference between the cathodic and anodic half-cell potentials, with a given anodic reaction (e.g. sulfide- vs. iron-oxidation) yielding a value characteristic of the dominant metabolic process. The measured potentials are distinct for each of the two wellbore locations, with sulfate-reduction dominating the response downgradient from the point of acetate injection. The SP phenomena will be presented at the Fall 2006 AGU meeting (Williams et al., 2006). Although more work is necessary to confirm our complex resistivity and SP observations, these exciting results further suggest that geophysical methods should be useful for monitoring system transformations in high resolution and in a minimally invasive manner.

2c). Petrophysics. In this component of the project, we are investigating the controls on the geophysical responses through development, augmentation, and testing of petrophysical models. During this year, we have explored the relationships between complex resistivity and seismic responses to the development of precipitates. For the complex resistivity, we have decided to work with a modified Cole-Cole model to link between electrical parameters with the volume of precipitates that are developed. For the seismic waveform data, are working with a doubleporosity, or patchy saturation model, to relate the seismic attributes to precipitate formation.

2d) Estimation Framework . We are developing a stochastic framework for estimation of timelapse geochemical parameters using extensive geophysical data, sparse geochemical data, and the petrophysical models, which were described in Section 2c. We are using a Markov Chain approach for this complex, multi-parameter estimation problem that builds on our previous work and that includes time and zonation associated with heterogeneity. The estimation framework will be presented at the Fall 2006 meeting (Chen et al., 2006). Development of this estimation framework will enable a more quantitative interpretation of the geophysical signatures than has been heretofore possible.

2e) Reactive Transport Modeling. This component focuses on validating and calibrating reactive transport models against the controlled laboratory experiments. We are using the pore-water chemistry determined over the course of lab experiments and the solid-phase mineralogy determined via post mortem analysis to develop a defensible description of the reaction network (pathways and rates). The reactive transport modeling is carried out using CRUNCH and TOUGHREACT codes. The reactive transport model is being calibrated to the geophysical data, but only by using the independent constraints provided by the microbiological, chemical, and physical data. This is a key step, since the geophysical data will be crucial in developing a highresolution data set at the field scale, where complete microbiological, chemical, and physical characterization of the subsurface material will not be feasible.

To date, modeling of precipitation rates using solute spatial profiles from previouslyconducted column experiments indicates $\mathrm{FeS}$ and $\mathrm{ZnS}$ accumulation rates that agree closely with those determined by $0.5 \mathrm{~N} \mathrm{HCl}$ extraction. Based on these results, the direct reaction of dissolved $\mathrm{H}_{2} \mathrm{~S}$ with magnetite present in the column appears to be negligible. However, careful analysis of the reaction stoichiometry of the columns (microbially-mediated sulfate reduction by 
Desulfovibrio vulgaris with injection of dissolved Fe(II)) indicates that an excess of sulfate is reduced relative to the available lactate that is injected as an electron donor. This implies that acetate is being used as an electron donor in some fashion. The most likely explanation involves the use of acetate plus $\mathrm{CO}_{2}$ as the carbon source and $\mathrm{H}_{2}$ (present in the anaerobic chamber) and sulfate as the energy source (Badziong et al., 1979), since Desulfovibrio vulgaris is not known to use acetate directly as an energy source. Research associated with the iteration between reaction transport predictions and geophysical monitoring of transformations will be presented at the Fall 2006 meeting (Hubbard et al., 2006).

3. Planned Activities. All five research areas will be advanced during the next year of the project Flow-through laboratory column experiments will be performed using rifle sediments and groundwater to explore the accuracy to which geophysical methods can be used to accurately indicate transformations important at the Rifle site. After pumping tests are completed, quantitative estimation of hydraulic conductivity will be performed using field-scale tomographic data using previously developed Bayesian approaches. We will continue to investigate the relationships between geophysical and biogeochemical properties using theoretical and experimental approaches. The estimation framework will be completed and tested using both laboratory and field-scale data. Finally, the reactive transport model will be further tested using the new column experiments, and prediction responses will be compared with geophysical monitoring estimates obtained using the estimation framework. The objective is to advance all components to the point where they can be used together during the final year of the project to predict, monitor, and validate field-scale transformations associated with field-scale biostimulation processes.

Several postdocs/students will join our team during the second year of this project. Postdoc Arash Massoudieh (from UC Davis, TR Ginn, advisor) will work closely with Carl Steefel on the reactive transport modeling component, Postdoc Andreas Englert (from the Forschungszentrum Jülich Laboratory in Germany) will work closely with Susan Hubbard on the estimation component, and Michael O'Brian (Rutgers) will work closely with Lee Slater on development of an advanced electrical petrophysical model.

4. Information Access. References for journal papers, book chapters, and abstracts (including several invited presentations) supported through this project are listed below. Additional information is available through http://esd.lbl.gov/sshubbard/monitoring.html and through the program website http://www.lbl.gov/NABIR/generalinfo/PI_ann_mtgs.html

Journal Papers (published, in press, in preparation)

1. Scheibe, T., Y. Fang, C.J. Murray, E. E. Roden, J. Chen, Y. Chien, S.C. Brooks, S. S. Hubbard, Transport and biogeochemical reactions of metals in a and chemically heterogeneous aquifer, Geosphere, 2(4), 220-245, doi: 10.1130/GES00029.1, 2006.

2. Kowalsky, M.B., S. Finsterle, J. Peterson, S. Hubbard, Y. Rubin, E. Majer, A. Ward, and G. Gee, Estimation of field-scale soil hydraulic and dielectric parameters through joint inversion of GPR and hydrological data, Water Resources Research, v. 41, W11425, doi: 10.1029/2005WRR004237, 2005.

3. Linde, H., S. Finsterle, and S. Hubbard, 2006 Inversion of hydrological tracer test data using tomographic constraints, Water Resources Research, v. 42, W04410, doi: 10.1029/2004WR003806, 2006.

4. Kowalsky, M.B., J. Chen, and S.S. Hubbard, Joint inversion of geophysical and hydrological data for 
improved subsurface characterization, The Leading Edge, Society of Exploration Geophysicists, V 26(5), 730-734, 2006

5. Linde, N., J. Chen, M. Kowalsky, and S. Hubbard, Hydrogeophysical Parameter Estimation at the Field Scale, Chapter 1 in Applied Hydrogeophysics, Springer Nato Science Series, V. 71, ed. H. Vereecken, p. 9-44, 2006.

6. S. Hubbard and Y. Rubin, Hydrogeological characterization using geophysical methods, Chapter 14 in The Handbook of Groundwater Engineering, CRC Press, Ed. J. Delleur, in press.

7. Williams, K.H., S.S. Hubbard, and J.F. Banfield, Monitoring Microbial Chemotaxis and Stimulated Sulfate-Reduction Using Galvanic Means, in preparation for Geophysical Research Letters, 2006.

8. Williams, K.H., J. Druhan, P.E. Long, S.S. Hubbard, and J.F. Banfield, Galvanic monitoring of stimulated subsurface microbial activity, in preparation for Environmental Science \& Technology, 2006.

\section{Abstracts}

1. Hubbard, S. K. Williams, J. Chen, J. Peterson, T. Scheibe, S. Mukhopadhyay, E. Sonenthal and C. Steefel, Improved Understanding of Natural System Processes through Coupling of Geophysical Characterization and Numerical Modeling Approaches, Invited Presentation, Fall 2006 AGU, San Fransicso.

2. Chen, J., S. Hubbard, K. Williams, A. Kemna, L. Slater, and S. Pride, A stochastic framework for geochemical parameter estimation using geophysical methods: development and application, Fall 2006 AGU, San Francisco.

3. Williams, K.H., Andreas Kemna, Phil Long, Jenny Druhan, Susan Hubbard, and Jill Banfield,, Following the Progress of Subsurface Bioremediation: Insights Gained from Field-Scale Geoelectrical Monitoring. Sulfide Biomineralization and Aquifer Geochemistry: What Role Do Geoelectrical Monitoring Methods Have to Play?, AGU Invited Presentation, 2006, San Francisco.

4. Hubbard, S., K. Williams and J. Chen, Characterizing Hydrogeological Properties and Monitoring Biogeochemical Processes using Geophysical Data, Invited Presentation, Groundwater Resources of California, Nov. 12-14, 2006, Long Beach, CA

5. Hubbard, S.S., K. H. Williams, A. Kemna, J. Chen and J. Peterson, Use of Geophysical Methods to Investigate, Guide, and Assess Contaminant Remediation Approaches, Invited Presentation for Session GSA T88, GSA Abstracts with Programs Vol. 38, No. 7.

6. Hubbard, S., J. Chen, Y. Fang, K. Williams, S. Mukhopadhyay, E. Sonnenthal, K. McFarlane, N. Linde and T. Scheibe, Improved parameterization of hydrological models and reduction of geophysical monitoring data ambiguity through joint use of geophysical and numerical modeling methods, Invited Keynote Speaker, CWMR, DN, June 19-23, 2006.

7. Williams, K.H., A. Kemna, S.S. Hubbard, and J.F. Banfield, Seeing in the dark: A geophysical approach to monitoring subsurface iron redox cycling, Invited Presentation, Telluride Summer Science Institute, Telluride, CO, July 2006.

8. Williams, K.H., P. Long, E. Shelobolina, J.E. Amonette, S.S. Hubbard, and J.F. Banfield, NonInvasive geophysical monitoring of clay-mineral transformations during stimulated $\mathrm{Fe}(\mathrm{III})$-reduction, International Symposium for Subsurface Microbiology, Jackson Hole, WY, August 2005.

9. Williams, K., S. Hubbard and K. MacFarlane, Biophysical monitoring: separating the 'bio' from the 'geo', Eos Trans. AGU, 87(36), Jt. Assem. Suppl., Abstract NS41A-06. BEST STUDENT PAPER AWARD. 